\title{
Neither questions nor answers, just original data
}

\section{To the Editor:}

We have read with interest the letter by EwIG [1] in relation to our article [2]. According to his opinion, our study raises an unproductive debate about the usefulness of bronchoscopic sampling techniques in ventilator-associated pneumonia (VAP).

As it is well known, most of the studies dealing with the diagnostic efficacy of bronchoscopic sampling techniques in VAP include a large percentage of patients already on antibiotics when the procedure is carried out. Owing to the different nature of the antibiotic treatment used in these series, the variable "prior antibiotics" suppose an important bias for the interpretation of the microbiological results. Furthermore, only a few studies provide adequate information concerning the nature of the previous antibiotic regimens and, consequently, as it has been recently emphasised [3] in this setting, the interpretation of the microbiological data is usually complex.

We designed our study in order to obtain prospective data that could demonstrate the effect of an adequate antibiotic regimen on susceptible strains obtained by protected specimen brush technique, before antibiotic treatment and at different periods of time after the introduction of the antibiotic. So far, very few studies have used a similar approach [4]. Our results demonstrate that some bacterial species appear to be highly vulnerable to antibiotics (Streptococcus pneumoniae, Haemophilus influenzae), whereas other organisms (Pseudomonas aeruginosa, Acinetobacter baumanii, Staphylococcus aureus) are still viable 48-72 $\mathrm{h}$ after starting an active antibiotic treatment.
We do not believe that our data can be taken as an argument in the controversy about the usefulness of bronchoscopic sampling techniques in ventilatorassociated pneumonia. They just demonstrate that in some cases, basically in the early onset ventilatorassociated pneumonia, a very short course of an appropriate antibiotic can provide false-negative results, and this has to be taken into account when defining the therapeutic strategy. In addition, it is possible that a similar antibiotic effect can be observed when using samples obtained by more simple sampling methods, such as endotracheal aspirates, but this, of course, has to be confirmed.

\section{E. Prats, J. Dorca, F. Manresa}

Servei de Pneumologia, Hospital de Bellvitge, L'Hospitalet de Llobregat, Spain.

\section{References}

1. Ewig S. Questions with inconclusive answers. Eur Respir J 2002; 20: 1064-1065.

2. Prats E, Dorca J, Pujol M, et al. Effects of antibiotics on protected specimen brush sampling in ventilatorassociated pneumonia. Eur Respir J 2002; 19: 944-951.

3. Chastre J, Fagon JY. Ventilator-associated pneumonia. Am J Respir Crit Care Med 2002; 165: 867-903.

4. Montravers P, Fagon JY, Chastre J, et al. Follow-up protected specimen brushes to assess treatment in nosocomial pneumonia. Am Rev Respir Dis 1993; 147: 33-34.

\section{Muscle weakness after short course of steroids}

\section{To the Editor:}

NAva et al. [1] have shown acute weakness of respiratory and skeletal muscles after a short course of methylprednisolone given for acute lung rejection after transplantation. As many chest physicians commonly use other corticosteroids, it is interesting to compare equivalent doses. Over a 5-day course of methylprednisolone [1] a $70 \mathrm{~kg}$ male would have received $\sim 3.9 \mathrm{~g}$. This is approximately equivalent to $4.9 \mathrm{~g}$ prednisolone or $19.5 \mathrm{~g}$ hydrocortisone [2].

I have previously suggested there is a dose effect with hydrocortisone in causing myopathy in ventilated asthmatics, with weakness more likely if $>5 \mathrm{~g}$ hydrocortisone was used [3]. Those patients were paralysed with neuromuscular blocking agents (which might predispose to myopathy), but severe weakness has also been described with $10.0 \mathrm{~g}$ hydrocortisone over 10 days in a nonparalysed ventilated asthmatic [4]. Methylprednisolone is often given in doses of $1.0 \mathrm{~g}$ and theoretically even 2 days treatment (equivalent to $10.0 \mathrm{~g}$ hydrocortisone) might be enough to cause weakness. NAvA et al. [1] have usefully highlighted the need to be aware of acute muscle weakness following high-dose steroids.

C.D. Shee

Queen Mary's Hospital, Sidcup, UK. 